\title{
A Transformative Approach to Social Work Education
}

\section{Lorenzetti, Liza ${ }^{a}$; Dhungel, Rita ${ }^{\mathrm{b}}$; Lorenzetti, Diane ${ }^{\mathrm{c}}$; Oshchepkova, Tatiana ${ }^{\mathrm{d}}$ and} Haile, Lemlem ${ }^{\mathrm{e}}$

${ }^{\mathrm{a}, \mathrm{b}, \mathrm{d}}$ Faculty of Social Work, ${ }^{\mathrm{c}}$ Department of Community Health Science, University of Calgary, Canada.

\begin{abstract}
The paper presents an overview of "The Journey Guides Program" - a mentorship and experiential learning framework developed by the Faculty of Social Work, University of Calgary in Canada. This program was implemented in an Advanced Graduate Seminar, a preparatory course for graduate Social Work students prior to entering their field placements. The purpose of this program is to advance practice-based knowledge in tranformative learning. This article begins by discussing critical pedagogy, the theoretical framework that underpinned "The Journey Guides Program", followed by a description of the eight-step process the authors adopted to implement this program. This paper concludes by presenting our evaluation plan and subsequent steps.
\end{abstract}

Keywords: Journey guides; transformative learning; mentorship; social work. 


\section{Introduction/Background}

Social work is a transformative profession that centralizes human rights and social justice work (International Federation of Social Workers, 2012). Social work students require transformative learning opportunities to engage them in a process of critical thinking to "expand consciousness through the transformation of basic worldview and specific capacities of the self" (Elias, 1997, p. 3). Critical pedagogy resonates with social work education as it is intended to "provoke the student to question all taken-for-granted values, ideas, norms, beliefs, etc. of her experience that are the given presuppositions comprising the dominant social paradigm" (Sagris, 2008, p. 1). In order to centralize transformative experiential learning in social work education, the University of Calgary's Faculty of Social Work developed a community mentors experiential learning framework entitled the "Journey Guides Program". This initiative was implemented in an advanced graduate seminar for students pursuing a specialization in international and community development. The seminar focuses on preparing graduate students to enter field placements in both local and international settings. This paper presents the theoretical lens that informed the initiative, the eight-step experiential framework that was used as a pedagogical tool to support student learning, and the preliminary plans for program evaluation. The purpose of the progam is to advance research-informed teaching in the area of tranformative learning.

\section{Literature Overview}

Essential competencies and skills required for the profession of social work include critical analysis, leadership, and actions to address and eliminate oppressive social and economic conditions (CASW, 2015). Increasingly, there is growing recognition of the importance of better preparing social work students to engage in critical and anti-oppressive practice (Dominelli, 2002; Fook, 2002; Mullaly, 2010). Transformative learning is an important tool to achevie this goal as it aims to assist students to develop autonomous thinking and question prevailing 'truths' (Mezirow, 1997; Bay \& Macfarlane, 2011). This is important to social work, which is a practice-based discipline, as research indicates that "experiential learning can serve as a vehicle to encourage students to become engaged citizens" (Heinrich, Habron, Johnson, \& Goralnik, 2015, p.273). While the literature suggests that experiential learning opportunities can promote transformative learning, "critical thinking is not necessarily a part of every experiential learning process" (Heinrich et al., 2015, p.273) and needs to be articulated as a key outcome. The capacity for critical thinking is particularly important to social work, and "educators are responsible for assisting students to develop their critically reflective capacity" (Bay \& Macfarlane, 2011, p.755). Community mentors or guides can assist students to navigate experiential learning endevors. Scholars expound the benefits of mentorship, which is both relational and 
experiential, in providing students with professional knowledge, skill-building opportunities, connections, and guidance (Schweibert, 2000). For example, a study by Venema, Ravenhorst Meerman, and Hossink (2015), note that connections with community-based practitioners enhanced student learning. There is limited research, however, on the role of mentorship and experiential activities in supporting transformative learning in social work education. Additionally, the impact of community-based experiential opportunities requires further research. Few studies have adopted critical pedagogical and transformative learning approaches to meet this objective. The Journey Guides Program sought to fill this gap in social work education by implementing and evaluating an experiential transformative learning framework, which included a mentorship component.

\section{Theoretical Lens and Rationale}

The Journey Guides Program was established as an experiential and relational learning initiative for graduate students. The purpose of the project is to advance teaching knowledge in transformative learning. The authors utilized our collective experiences of more than eighty years of practice and teaching to design the progam. Our team included two instructors in the specified graduate program, an alumni, an experienced community organizer and an expert in mentorship research. An essential element of the program, community-based practitioners involved in social justice work were recruited as "Journey Guides" to provide one-to-one mentorship and support to students. Journey Guides were defined for this project as: social workers (or related professionals) with community organizing experience and cultural knowledge related to a student's potential or selected practice region or population.

Specific program goals were established: 1) enhance knowledge, experiences and competencies of students in community development practice; 2) promote experiential learning opportunities for students through critical dialogues and actions; 3 ) build students' personal and professional networks; 4) help students recognize their aspirations and choose potential field placements; and 5) assist students to develop an interest in mentorship as a social work practice. With these aims, an eight-step process was established is presented in the following section. 


\section{Implementation of the Program}

Building on the project rationale and the transformative learning goals discussed in the previous section, an eight-step program implementation process was developed. The steps were implemented in Year 1 and will be modified based on the findings from our program evaluation. (See Figure 1). Sixteen graduate students and eighteen Guides participated in the Journey Guides Program in Year 1. The Guides' involvement in this program was completely voluntarily and they did not receive remuneration.

\subsection{Step 1: Community supper}

At the beginning of the term, both students and Journey Guides were invited to participate in a "community supper" in the Faculty of Social Work in order to set the context for the year-long relationship among Guides, students and course instructors. This community event contained key elements such as networking opportunities, motivational presentations from Guides on local and global social justice issues, and the sharing of a meal. This first event underscored the importance of relational learning and the value of community-based experiences. It also centralized social justice while at the same time offering an ambience with music and enjoyment.

\subsection{Step 2: Aspirations assignment}

Students were asked to complete an "Aspirations Assignment" and deliver a two-minute "Elevator Speech" to their peers and the course instructors. This assignment helped them to reflect on their goals and plans for the year related to their graduate program and assisted the instructors to match each student with a Guide.

\subsection{Step 3: World Café Exchange}

A World Café event (Brown, 2001) was organized for both students and Guides that focused on relationship-building and knowledge exchange. From this event, a number of relationships were formed and students were able to acquire practical knowledge from experienced practitioners. 


\subsection{Step 4: Matching process}

Each student was matched with a Guide based on their Aspirations Assignments and recommendations that emerged from the two experiential activities (supper and World Café). Students were provided with their Guide's profile. An introduction letter was sent to both students and Guides to complete the match.

\subsection{Step 5: Agreement}

During the matching process, an "Agreement Letter" was distributed to students and Guides to facilitate the first meeting. The agreement was developed from existing research in the area of mentorship, and focused on purpose, expectations, respect and professional boundaries. Each Guide committed to meeting with a graduate student for a minimum of three times throughout the year, and many attended class gatherings and subsequent events.

\subsection{Step 6: Mentorship workshop for both students and Journey Guides}

Recognizing the need for mentorship training, two mentorship training workshops were offered for both Guides and students. The workshop provided participants with an opprotunity to gain a better understanding of mentor/mentee roles and also helped them to reflect on their respective roles.

\subsection{Step 7: Mentorship meet-ups}

Guides and students were asked to arrange an intial meeting within the first six weeks of the program and second and third meetings at the mid-point and end of the course. Students were required to prepare questions for their Guides and classtime was used to plan for these meetings.

\subsection{Step 8: Feedback loops and further meetings}

Feedback on the program was elicited from students during classroom discussions. Instructors facilitated ongoing communication with the Guides through email and invitations to attend specific class events and activities. 


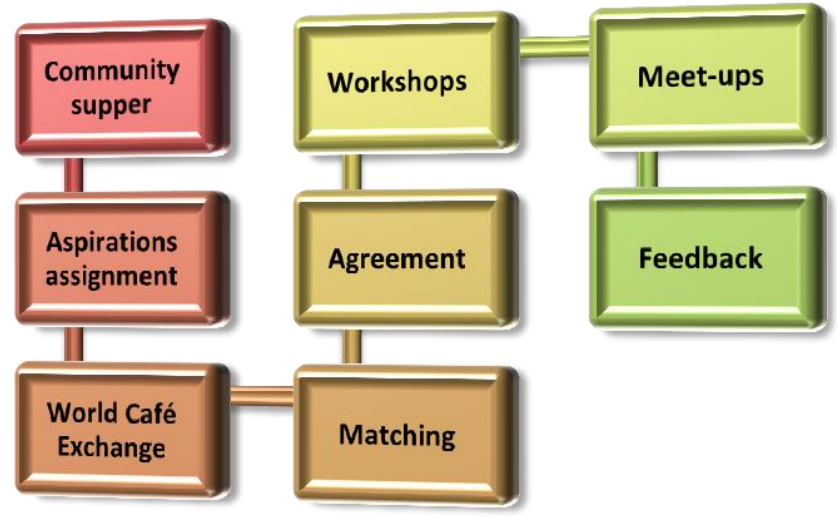

Figure 1. Implementation of the Program

\section{Evaluation Method}

Following the first year of program implementation, the authors designed an evaluation plan to assess the benefits and challenges of the program. The research, currently underway, employs a mixed-method design over a two year period. This includes focus groups with both students and Journey Guides from Year 1 and 2. An online survey is also distributed to students upon the completion of their study program. Our plan is to evaluate the impact of this experiential learning process (with cohort 1), refine our framework, and implement and evaluate it with the second cohort of students. Key concepts assessed through this evaluation include the student's understanding of their roles in social work, in community organizing and as advocates for social justice. A three-phase process of thematic analysis (Guest, 2012) will be used to analyze the data from Year 1 and 2. The evaluation is funded through a Teaching and Learning Grant provided by the Taylor Institute for Teaching and Learning at the University of Calgary.

\section{Discussion and Implications}

The profession of social work is founded on the tenets of social justice and human rights. In a world with high levels of inequality, violence and ecological harm, there is an increasing call within social work to centralize these core ethical concepts in ways that produce tangibe outcomes. As a response to the need for tranformative learning within social work, a critical pedagogical lens was used to design a transformative experiential learning initiative for graduate social work students. Through the implementation of this program, students were provided with opportunities to engage with community Guides and participate in community-based experiential activities. An evaluation of this program is currently underway, guided by an interdisciplinary research team, including the two course 
instructors who were involved in the progam's design. The findings will centralize concepts that are of key importance to social work, including the student's ability to expand their networks of influence and their roles as social justice advocates. 


\section{References}

Bay, U., \& Macfarlane, S. (2011). Teaching Critical Reflection: A Tool for Transformative Learning in SocialWork? Social Work Education, 30(7), 745-758.

Braun, V., \& Clark, V. (2006). Using thematic analysis in psychology. Qualitative research in psychology, 3(2), 77-101.

Brown, J. (2001). The World Café: Living knowledge through conversations that matter. (Unpublished doctoral dissertation). Fielding Graduate University, CA, USA

Canadian Association of Social Workers (2005). CASW code of ethics. Retrieved from http://www.casw-acts.ca/en/what-social-work/casw-code-ethics

Canadian Association of Social Workers. (2015). About CASWE. Retrieved from http://www.casw-acts.ca/en/about-casw

Dominelli, L. (2002). Anti-oppressive social work theory and practice. Hampshire, ENG: Palgrave, MacMillan.

Elias, D. (1997). It's time to change our minds: An introduction to transformative learning. ReVision, 20(1), 2-7.

Fook, J. (2002). Social work: Critical theory and practice. London, ENG: Sage.

Freire, P. (1970). Pedagogy of the oppressed. New York, NY: Continuum.

Guest (2012). Applied thematic analysis. Thousand Oaks, CA: Sage.

Heinrich, W. F., Habron, G. B., Johnson, H. L., \& Goralnik, L. (2015). Critical Thinking Assessment Across Four Sustainability-Related Experiential Learning Settings. Journal of Experiential Education, 38(4), 373-393.

International Federation of Social Workers. (2012). Statement of Ethical Principles. Retrieved from http://ifsw.org/policies/statement-of-ethical-principles/

Lorenzetti, L. \& Walsh, C. (2014). Is there an 'F' in your PAR? Understanding, teaching and action research. Canadian Journal of Action Research, 15(1), 50-63

Mezirow, J. (1997). 'Transformative learning: theory to practice', in New Directions for Adult Education and Continuing Education, Jossey-Bass Publishers, San Francisco, CA, pp. 5-12.

Mullaly, B. (2010). Challenging oppression and confronting privilege (2nd ed.). Don Mills, ON: Oxford University Press Canada.

Sagris, J. (2008). Liberatory education for autonomy. The International Journal of Inclusive Democracy, 4(3), 1-4. 
Schweibert, V. L. (2000). Mentoring: Creating connected, empowered relationships. Alexandria, VA: American Counseling Association.

Venema, R., Ravenhorst Meerman, J., \& Hossink, K. (2015). Experiential, team-Based learning in a baccalaureate social work research course. Journal Of Teaching In Social Work, 35(5), 471-492. doi:10.1080/08841233.2015.108793 